\title{
Propriedade intelectual na cadeia de flores e plantas ornamentais: uma análise da legislação brasileira de proteção de cultivares*
}

\author{
Camila Dias de Sá ** $^{*}$ \\ Maria Sylvia Macchione Saes***
}

Recebido: 27/08/2013 Versão Revisada (entregue): 11/12/2013 Aprovado: 15/01/2014

\begin{abstract}
Resumo
Este artigo aborda os impactos da Lei de Proteção de Cultivares (LPC) na cadeia brasileira de flores e plantas ornamentais. Um dos resultados diretos da lei foi o estímulo à inovação. Entretanto, surgiram também custos de transação para as empresas que operam no país. Em virtude da falta de clareza do dispositivo de uso próprio presente na LPC, tal lei não assegura a proteção eficaz das espécies de plantas propagadas vegetativamente. Desse modo, os melhoristas estrangeiros adotaram contratos específicos, parcialmente sustentados pelo regime de propriedade intelectual existente. Com base em entrevistas semiestruturadas com melhoristas, produtores e distribuidores de flores, o artigo explora a especificidade de experiências concretas e faz recomendações para o aprimoramento das condiçôes de comercialização e investimento na floricultura nacional.
\end{abstract}

PALAVRAS-CHAVE | Direitos de Propriedade; Inovação; Variedades Vegetais

Códigos JEL | K11; O31; O34

\footnotetext{
* Os autores agradecem o apoio da Capes, do Centro de Estudos das Organizaçōes (CORS), das organizaçôes e produtores entrevistados e das sugestôes dos pareceristas anônimos.

** Universidade de São Paulo (USP), São Paulo (SP), Brasil. E-mail: camiladias@usp.br

*** Universidade de São Paulo (USP), São Paulo (SP), Brasil. E-mail: ssaes@usp.br
} 


\title{
Intellectual property rights in the flower chain: an analysis of the Brazilian plant variety protection system
}

\begin{abstract}
The paper addresses the impacts of the Brazilian Plant Variety Protection (PVP) System on the flower chain. While the system has stimulated the marketing of new varieties of plants it has also raised transactions costs for companies operating in the country. Because the farmers' privilege provision is not well delineated within the national jurisprudence, protection of property rights may became ineffective for asexually reproduced plants. In order to deal with such situation, foreign breeding companies have adopted specific contractual arrangements partially supported by the existing intellectual property rights regime. Based on semi-structured interviews with breeders, flowers growers and wholesalers, the paper explores the specificity of concrete experiences in the Brazilian market and advances policy recommendations that may serve for the improvement of marketing and investment conditions at the flower chain.
\end{abstract}

KEYwORDS | Property Rights; Innovation; Plant Varieties

JEL-CODES: K11; O31; O34 


\section{Introdução}

A proteção de cultivares significa o reconhecimento da propriedade intelectual (PI) sobre novas variedades vegetais. Exercida por meio da adoção de instrumentos de privilégio, trata-se de uma instituição criada para propiciar a inovação. A finalidade deste instrumento é garantir a apropriação de resultados econômicos como forma de remunerar os recursos utilizados e riscos assumidos no desenvolvimento de novas variedades vegetais.

Os regimes de proteção de cultivares estimulam os investimentos em pesquisa de novas variedades, contribuem para o desenvolvimento do setor doméstico de sementes e outros materiais propagativos e ainda permitem que as nações tirem proveito de materiais estrangeiros para aprimorarem seus programas de melhoramento de plantas. A promoção desses programas é considerada parte de políticas públicas para garantir a segurança alimentar dos países (LESSER, 1997).

No entanto, alguns grupos são mais cautelosos sobre os benefícios dos sistemas de proteção de cultivares e enxergam perigos potenciais em termos de concentração de tecnologia nas mãos de poucas empresas e restrições à atuação dos agricultores (TRIPP et al., 2007).

Considerando tal contexto, este artigo tem o objetivo de verificar, pela ótica dos agentes que atuam no mercado de flores, especialmente produtores e melhoristas, como este mercado tem sido influenciado pela Lei de Proteção de Cultivares (LPC). ${ }^{1} \mathrm{O}$ interesse é entender o papel desempenhado pela LPC na proteção da PI de novas variedades de flores e na promoção de inovação na floricultura brasileira.

A referida lei trata do reconhecimento da PI sobre novas variedades vegetais, por meio da concessão de certificado de proteção emitido pelo Serviço Nacional de Proteção de Cultivares (SNPC), Ministério da Agricultura, Pecuária e Abastecimento (Mapa). O título garante direito de exclusividade aos obtentores (melhoristas) de plantas para exploração comercial.

A legislação em pauta contemplou a prática de "uso próprio", tradição dos agricultores de guardarem os melhores grãos de uma safra para serem utilizados como sementes na safra seguinte. A preocupação com a segurança alimentar e a viabilidade econômica dos pequenos produtores são os fatores que estão por trás do dispositivo de uso próprio. Contudo, em virtude de tal dispositivo, admite-se que a lei não assegura a proteção eficaz das espécies de plantas propagadas vegetativamente, nas

1 Lei $n^{\circ} 9.456$, de 25 de abril de 1997. 
quais se inclui a maioria das flores de corte. $\mathrm{O}$ uso próprio expóe as variedades à "pirataria”, o que significa que a proteção fornecida pela LPC é insuficiente, especialmente do ponto de vista dos obtentores. ${ }^{2}$

Assim, a hipótese trabalhada neste estudo aventa se a LPC, conforme concebida, implica custos de transação que, por sua vez, condicionam um desempenho da cadeia brasileira de flores e plantas ornamentais inferior ao esperado com a sanção da lei.

Para verificar o que se propõe, foram analisados dados relativos à proteção de variedades de rosa, gérbera e alstroemeria. Também foram realizadas entrevistas semiestruturadas com agentes da cadeia produtiva em questão envolvidos direta ou indiretamente com a proteção de cultivares, a saber: melhoristas brasileiros e estrangeiros, produtores e distribuidores de flores.

Este artigo está estruturado em cinco seções, incluindo esta introdução. $\mathrm{Na}$ segunda, são apresentadas consideraçôes sobre a interação entre as instituições formais e informais na configuração do regramento da proteção de cultivares. A terceira expõe um breve histórico sobre como este regramento foi constituído internacionalmente e introduzido no Brasil. Abordam-se a questão do uso próprio e as implicações para a apropriação dos direitos de propriedade intelectual (DPIs) relativos às variedades de flores.

A quarta seção discute e analisa os resultados das entrevistas semiestruturadas e alguns números relativos à proteção de variedades das flores selecionadas para o estudo. Entre os principais resultados, destaca-se o estímulo à inovação na cadeia produtiva estudada, ainda que parcial, já que o resultado positivo tem sido capturado especialmente por organizações estrangeiras. As considerações finais, que sugerem o aprimoramento da LPC, e as recomendações de pesquisas futuras são apresentadas na quinta seção.

\section{A proteção de cultivares sob o enfoque institucional}

As instituições formais e informais são complementares na criação de resultados econômicos específicos e o desenho de regras formais eficientes deve levar em consideração a interação entre as regras formais e informais (EGGERTSSON, 1996). No campo da biotecnologia, Silveira e Borges (2004) entendem que, em virtude de tal interação, as instituições criam uma rede de relações contraditórias, que pode tanto estimular como retardar o progresso técnico.

2 Na reprodução vegetativa um organismo não necessita de outro indivíduo para se reproduzir. Os produtores de flores de corte precisam de poucas partes de plantas para produzir uma numerosa quantidade de plantas idênticas. 
A relação entre as instituições formais e informais é explicitada por Aoki (2007), ao admitir que as normas não podem ser simplesmente impostas exogenamente nem transplantadas de um local para outro, precisando ser recriadas por açōes diárias repetitivas.

Segundo Eaton e Meijerink (2007), uma das questôes que deve ser considerada em um processo de mudança institucional é se as regras e as estruturas de governança que são bem-sucedidas em uma situação podem ser aplicadas em outra. Os autores afirmam que os arranjos institucionais devem se encaixar no ambiente institucional que, por sua vez, deve ser acomodado nas normas sociais. Se não houver equivalência, então, o regime organizacional e as regras formais podem ser ignorados, ineficazes, ou levar a consequências indesejadas.

Os acordos internacionais de proteção de cultivares são instituições formais com origem nos países desenvolvidos que servem como regra exógena para referenciar as relações entre naçôes em torno da proteção à PI em plantas. Carvalho (2003) argumenta que esses acordos criaram padrões de referência de legislações que possibilitam aos países signatários obter e oferecer proteção equivalente de cultivares.

Nesse sentido, em termos institucionais, existem duas razões para que as normas internacionais de proteção gerem resultados distintos entres as sociedades: a primeira, em função das adaptaçôes e critérios adotados pelos legisladores, decorrentes da autonomia que é facultada aos países; e a segunda, pela forma como interagem com as instituiçôes informais. Tal interação determina como os DPIs serão definidos e alocados entre os agentes envolvidos em certo mercado.

Quando os direitos de propriedade estão claramente definidos e há formas de garantir sua aplicação, os custos de transação são reduzidos, o que estimula investimentos e favorece o desenvolvimento econômico (NORTH, 1990).

A proteção de cultivares não é neutra em seus efeitos sobre empresas e países: exigências e custos envolvidos na busca e no enforcement da proteção têm impactos diferenciados entre ambos, tendendo a reforçar a assimetria de capacidade de inovação entre países desenvolvidos e os demais e alimentar os debates sobre a eficácia do sistema de proteção da PI como instrumento de promoção do desenvolvimento (VIEIRA et al., 2010).

Autores como Scotchmer (2004), Diez (2002), Falcon e Fowler (2002), Lence et al. (2005) e Eaton (2008) investigaram a relação da proteção de cultivares com o desenvolvimento econômico e encontraram resultados mistos.

Gallini e Scotchmer (2003) afirmam que a utilização dos DPIs como incentivo à inovação depende da facilidade com que os inovadores podem realizar acordos para 
organizar e exercer seus direitos. Os instrumentos privados de contratação podem ser complementares na redução dos custos sociais de um regime de proteção muito abrangente ou insuficiente.

Esse artigo busca, portanto, discutir como a proteção de cultivares introduzida no Brasil a partir da sanção da LPC tem moldado a cadeia produtiva de flores e plantas ornamentais. São abordados especificidades da legislação e os custos de transação resultantes, bem como os contratos utilizados para garantir a apropriação dos DPIs pelos melhoristas de flores. Em última instância, este artigo ainda evidencia como a LPC tem contribuído para a inovação e desenvolvimento econômico do setor.

\section{As flores e a proteção de cultivares}

A LPC foi sancionada em 1997 em decorrência dos compromissos firmados por meio do acordo Trips (Acordo de Propriedade Intelectual Relacionado ao Comércio), estabelecido em 1994 na Rodada do Uruguai de Negociações Comerciais Multilaterais do Gatt (mais tarde, OMC). ${ }^{3}$

Após ratificar sua adesão, o Brasil tornou-se obrigado a alterar legislação antiga que não dispunha sobre biotecnologia. O país optou por adotar um sistema único, sui generis de proteção, integrando-se desde 1999 ao sistema Upov (União para a Proteção de Obtenções Vegetais). ${ }^{4}$

A LPC estabeleceu mecanismos para reconhecimento do direito de PI sobre novas variedades vegetais, conferindo aos melhoristas um certificado de proteção com direitos de exclusividade para exploração comercial. Desse modo, o país passou a ter um aparato legal que protege os direitos dos melhoristas. ${ }^{5}$

3 O acordo Trips estabelece que: "os membros poderão excluir da patenteabilidade as plantas e animais [...]. Contudo, os membros devem prover proteção às variedades de plantas, seja por meio de patentes, por um sistema sui generis eficaz ou por qualquer combinação destes" (TRIPS, 1994, p. 331). Wilkinson e Castelli (2000) definem os direitos sui generis como uma adaptação legal visando a proteção da PI em casos como o das plantas que não se encaixam nas proteçôes clássicas.

4 A Upov é uma organização intergovernamental, cujo objetivo é estabelecer regras gerais e zelar pela proteção de novas variedades de plantas por meio de direitos de PI chamados de PBR, Plant Breeder's Rights, (direitos dos obtentores de plantas).

5 Para ser passível de proteção, uma cultivar é submetida ao teste DHE (distinção, homogeneidade e estabilidade) para comprovação de seus atributos únicos. A cultivar é distinta quando apresenta diferenças claras de qualquer outra cuja existência na data do pedido de proteção seja reconhecida; é homogênea quando, plantada em escala comercial, apresenta variabilidade mínima quanto às características que a identificam; e é estável quando, reproduzida em escala comercial, mantém sua homogeneidade por geraçōes sucessivas. Deve possuir ainda o atributo "novidade”, ou seja, uma cultivar não pode ser protegida se estiver há mais de um ano sendo comercializada no próprio país ou há mais de quatro anos no exterior (UPOV, 2005). 
No entanto, agentes da cadeia de flores e plantas ornamentais entendem que o dispositivo de uso próprio presente na LPC não está claramente definido e, portanto, não garante a proteção efetiva das espécies propagadas vegetativamente. Ao contrário, tal instrumento expõe essas espécies à pirataria, já que são facilmente reproduzíveis. Este é o caso da maioria das flores de corte.

A LPC define em seu artigo 10, parágrafo I, que:

Não fere o direito de propriedade sobre a cultivar protegida aquele que:

$I$ - reserva e planta sementes para uso próprio, em seu estabelecimento ou em estabelecimento de terceiros cuja posse detenha (BRASIL, 1997).

O dispositivo de uso próprio intenciona garantir a segurança alimentar e econômica da agricultura de escala familiar, bem como preservar a genética de variedades vegetais tradicionais. No entanto, tal instrumento tem sido utilizado para justificar a armazenagem de qualquer volume de sementes ou mudas, sem considerar a finalidade da lavoura.

Para Nogueira (2006), mesmo que o uso próprio tenha sido introduzido para favorecer a viabilidade econômica dos agricultores familiares que poderiam economizar na compra de sementes, seria necessário estabelecer um limite superior para a escala de produção ou renda do produtor. A permissão ilimitada ao uso próprio presente na LPC é considerada, por alguns atores, uma "brecha" que ocasiona o desrespeito à PI. Abre-se uma oportunidade para que os produtores guardem quantidades maiores do que o necessário para seu uso e comercializem o excesso em transações ilegais (NOGUEIRA, 2006).

Assim, a utilização de material propagativo a partir da colheita da safra anterior com a justificativa de uso próprio tem ocorrido de maneira demasiada. Alega-se que, para os melhoristas de flores reproduzidas vegetativamente, essa prática tem resultado em dificuldade de apropriação das inovações e causado desestímulo à continuidade dos esforços de P\&D direcionados ao Brasil (VAN ROOIJEN, 2006). ${ }^{6}$

No elo da produção a justificativa do uso próprio não procede, por se tratar de espécies cujo cultivo não tem finalidade alimentar. Adicionalmente, em função do tamanho do mercado no país e da grande diversidade de flores produzidas, o preço de uma cultivar é altamente influenciado pela quantidade de material ofertado.

6 Aviani (2009) afirma que a LPC é complementada pela Lei de Sementes e Mudas, que determina que o uso próprio deve ser informado previamente ao Mapa, assim como quais cultivares estão sendo multiplicadas. Para a propagação de cultivar protegida é preciso obter autorização do obtentor e a fiscalização é feita pelo Mapa. (Informação verbal fornecida por Aviani na Conferência Ciopora sobre direitos dos obtentores de plantas em Campinas, 2009). 
Assim, segundo Van Rooijen (2006), qualquer propagação, ainda que para efetivo uso próprio, implica significativo impacto no mercado, com redução significativa dos ganhos dos agricultores dedicados à produção comercial.

No caso em tela, são muitas as externalidades positivas geradas na obtenção de uma nova variedade de flor. Novos conhecimentos e novos atributos de produtos são concebidos, tais como maior produtividade, maior resistência a pragas e doenças, cores diferenciadas, entre outros. No entanto, em virtude do dispositivo de uso próprio presente na LPC, que não define claramente a alocação dos direitos sobre as novas variedades, externalidades negativas também podem surgir.

Eggertsson (1996) menciona o caso em que a utilização de um ativo, cujos direitos são detidos por um indivíduo, gera sobre o mesmo ativo externalidades negativas para outras utilizaçôes, cujos direitos são detidos por outrem. $\mathrm{O}$ agricultor detém o material propagativo que é um ativo físico, porém, esse ativo possui outros atributos que são de propriedade do obtentor da variedade. Se o produtor não respeita os DPIs do obtentor, ele está gerando externalidades negativas para este agente.

A definição dos direitos de PI no âmbito das cultivares, por meio da criação de um regramento como a LPC, intencionou a internalização das externalidades negativas geradas no processo de obtenção de novas cultivares. Porém, sem a clara definição da propriedade na lei, as novas variedades podem ficar disponíveis para os indivíduos utilizá-las sem custo, ou seja, essas variedades e seus atributos diferenciados podem cair em domínio público, com possibilidade de apropriação sem a adequada recompensa aos seus criadores.

Tripp et al. (2006) e Louwaars (2007) ressaltam que, em países sem tradição exportadora de flores, como é o caso do Brasil, a proteção por meio de um sistema eficaz de Proteção às Variedades de Plantas (PVP) é particularmente importante. Os autores lembram que devem ser estruturados níveis apropriados de proteção para diferentes tipos de produtos e que dispositivos mais restritivos podem ser aplicados seletivamente para casos particulares, em que incentivos comerciais justifiquem a proteção adicional, como é o caso das flores.

7 A ata de 1991 da Upov estipulou como objeto de proteção o produto da colheita, quando obtido pelo uso não autorizado do material propagativo, nos casos em que os obtentores não tiverem oportunidade anterior de exercer o seu direito. Segundo Tripp et al. (2007), esse dispositivo é útil para o mercado de exportação de flores. Os royalties devidos podem ser cobrados sobre os produtos comercializados nos mercados atacadistas da Europa, nos casos cujo material propagativo - que seria o objeto inicial da proteção - foi plantado em países exportadores que não possuem um sistema de PVP em operação, ou cuja proteção é pouco efetiva. 
Em 1980, a Holanda permitiu aos seus agricultores, em geral, a prática de uso próprio, porém, foi proibida a reserva de material propagativo da safra anterior especificamente para os produtores de flores de corte (LOUWAARS et al., 2005). Conforme relatado por Tripp et al. (2007), essa posição contribuiu intensamente para o desenvolvimento econômico holandês. Os autores explicam que os agentes envolvidos com o negócio de flores no país entenderam que o uso de material propagativo sem autorização do obtentor representava um grande desincentivo para o investimento na atividade de melhoramento.

Em 2003, a Colômbia, um dos maiores produtores e exportadores de flores, proibiu os agricultores com área superior a cinco hectares de utilizarem material propagativo da safra anterior para uso próprio. Desde então, produtores com área inferior ao estipulado devem encaminhar solicitação ao órgão responsável e fornecer detalhes de como o material propagativo será utilizado (LOUWAARS et al., 2005).

Endres e Goldsmith (2007) argumentam que, quando o regramento jurídico falha ou é inexistente, as empresas precisam se adaptar ao ambiente por meio de outras estratégias de apropriação dos seus direitos. Fuck (2009) observa que a falta de uma legislação clara pode dar margem a formas alternativas de proteção, as quais, em alguns casos, podem ampliar significativamente os direitos dos obtentores, indo além das orientaçôes da Upov. $\mathrm{O}$ autor destaca que se esses arranjos alternativos, por um lado, estimulam as atividades de pesquisa dos melhoristas, por outro, podem limitar os direitos dos produtores.

\section{0 impacto da LPC sob a óptica de melhoristas, produtores e distribuidores de flores}

As discussões e análises conduzidas nesta seção resultam, em grande parte, de entrevistas semiestruturadas realizadas com melhoristas, produtores e distribuidores de flores, perfazendo um total de 29 entrevistados. ${ }^{8}$ Também foram coletados e analisados dados primários e secundários relativos à proteção de variedades de rosa, gérbera e alstroemeria. ${ }^{9}$

As entrevistas realizadas com os melhoristas tiveram o objetivo de verificar como a LPC tem impactado nos negócios realizados por essas empresas no Brasil.

8 Todas as organizaçôes cujos nomes são citados concederam autorização para divulgação das informaçôes. As entrevistas foram realizadas em 2010.

9 Foram escolhidos os três gêneros que no início da pesquisa possuíam o maior número de certificados de proteçāo. Os dados primários foram obtidos em um centro de comercialização de Holambra e nas entrevistas. 
Já as entrevistas com produtores e distribuidores de flores tiveram a finalidade de complementar a verificação do impacto da LPC na floricultura brasileira.

A escolha das entrevistas semiestruturadas como instrumento de pesquisa baseou-se em Eaton e Van Tongeren (2004), que utilizaram tal instrumento para identificar os efeitos de sistemas de PVP nos negócios e decisões de investimento de empresas de melhoramento de plantas que operam globalmente.

Esses autores afirmam que a utilização desse instrumento para obtenção das percepções e das experiências dos agentes, apesar de ser custosa em termos do tempo requerido para análise das informações, ajuda na identificação de questôes-chave para pesquisas com objetivos amplos, bem como na revelação da riqueza de experiências dos entrevistados. Ademais, como as informaçōes sobre a floricultura brasileira são, em geral, escassas e muitas vezes divergentes, as entrevistas constituem um método valioso para o levantamento de informações que não se encontram organizadas de forma sistemática.

\subsection{Melhoristas brasileiros}

Foram entrevistadas uma organização privada, a ProClone, e uma pública, o Instituto Agronômico de Campinas (IAC). As entrevistas foram definidas por conveniência, já que o melhoramento realizado por instituições brasileiras ainda é incipiente e não se dispõe de dados sobre a sua participação de mercado.

A ProClone é uma empresa privada com sede em Holambra que se dedica a atividades de propagação de flores, entre estas, o melhoramento do gênero zantedeschia (copo de leite colorido). O IAC é um órgão de pesquisa da Agência Paulista de Tecnologia dos Agronegócios (Apta), da Secretaria de Agricultura e Abastecimento de São Paulo. Entre as atividades desenvolvidas pelo Instituto, está o melhoramento genético de algumas flores e plantas ornamentais, como o antúrio. O Quadro 1 traz um sumário das implicações extraídas das entrevistas.

As duas organizaçôes consideram a LPC importante porque tem disciplinado a cadeia produtiva, apesar dos problemas que a lei ainda possui. A percepção de ambos, no entanto, é de que os benefícios proporcionados ainda estão muito restritos a Holambra e ao Estado de São Paulo.

Em se tratando do negócio individual de cada entrevistado, a LPC foi positiva para a ProClone porque o ambiente criado tem proporcionado melhores condiçóes para a atividade da empresa. No caso do IAC, até a data da entrevista não era possível avaliar, já que o Instituto não possuía nenhuma variedade ornamental protegida. 
QUADRO 1

Implicações extraídas das entrevistas com os melhoristas brasileiros

\begin{tabular}{|c|c|c|}
\hline Questóes & Consideraçōes ProClone & Considerações IAC \\
\hline $\begin{array}{l}\text { Como a cadeia brasileira de } \\
\text { flores e plantas ornamentais } \\
\text { foi impactada pela LPC? }\end{array}$ & $\begin{array}{l}\text { - Positivamente apenas em } \\
\text { algumas regiōes. } \\
\text { - Necessário replicar o } \\
\text { modelo de sucesso "São } \\
\text { Paulo/Holambra” para } \\
\text { explorar a biodiversidade } \\
\text { ornamental brasileira. } \\
\text { - Para a organização: } \\
\text { condiçōes para } \\
\text { estruturaçãa do } \\
\text { melhoramento do gênero } \\
\text { escolhido. }\end{array}$ & $\begin{array}{l}\text { - Presença maciça de } \\
\text { melhoristas estrangeiros. } \\
\text { - Mercado começa a ser } \\
\text { disciplinado apesar de } \\
\text { "brechas". } \\
\text { - Cumprimento da lei ocorre } \\
\text { de maneira regionalizada } \\
\text { (Holambra). } \\
\text { - Para a organização: práticas } \\
\text { "politicamente incorretas" } \\
\text { de produtores que agem } \\
\text { respaldados pela legislação } \\
\text { falha. }\end{array}$ \\
\hline $\begin{array}{l}\text { Por que o número de } \\
\text { variedades ornamentais } \\
\text { brasileiras protegidas é } \\
\text { bastante reduzido? }\end{array}$ & $\begin{array}{l}\text { - Custo alto para obtenção } \\
\text { do certificado (1). }\end{array}$ & $\begin{array}{l}\text { - Custo alto para obtenção do } \\
\text { certificado. } \\
\text { - No IAC ainda é preciso } \\
\text { sensibilizar os pesquisadores } \\
\text { e criar uma política interna } \\
\text { sobre o tema. }\end{array}$ \\
\hline $\begin{array}{l}\text { Por que a atividade de } \\
\text { melhoramento de flores e } \\
\text { plantas ornamentais pouco } \\
\text { se desenvolveu após a sanção } \\
\text { da LPC e do ingresso do } \\
\text { Brasil na Upov? }\end{array}$ & $\begin{array}{l}\text { - Custo alto da atividade e } \\
\text { dependência de recursos } \\
\text { públicos. } \\
\text { - Laços culturais entre } \\
\text { Holambra e empresas } \\
\text { holandesas inibe o } \\
\text { melhoramento doméstico. }\end{array}$ & $\begin{array}{l}\text { - Problemas na lei, como o } \\
\text { uso próprio, desestimulam } \\
\text { investimentos. } \\
\text { - Custo alto da atividade e } \\
\text { dificuldade em obter recursos. } \\
\text { - Custo alto para obtenção de } \\
\text { certificado de proteção. } \\
\text { - Baixa demanda do } \\
\text { consumidor brasileiro por } \\
\text { flores e plantas. } \\
\text { - Desconhecimento da lei, } \\
\text { organizaçóes ainda não } \\
\text { aprenderam como usufruir } \\
\text { das possibilidades propiciadas. }\end{array}$ \\
\hline $\begin{array}{l}\text { Quais são os instrumentos } \\
\text { utilizados para apropriação } \\
\text { dos direitos sobre as novas } \\
\text { variedades desenvolvidas? }\end{array}$ & $\begin{array}{l}\text { - Contratos com produtores } \\
\text { coligados. } \\
\text { - Cuidados na escolha } \\
\text { de parceiros e seu } \\
\text { monitoramento constante. } \\
\text { - Construção de } \\
\text { relacionamentos de } \\
\text { confiança. }\end{array}$ & $\begin{array}{l}\text { - Contratos não exclusivos com } \\
\text { multiplicadores. } \\
\text { - "Luta" por recolhimento de } \\
\text { royalties. } \\
\text { - Pretensão de formular } \\
\text { políticas de disponibilização } \\
\text { do materiais conforme classes } \\
\text { de produtores. }\end{array}$ \\
\hline
\end{tabular}

Fonte: Elaboração das autoras.

(1) As taxas cobradas pelo SNPC partem de R\$1.200,00 por variedade. Os melhoristas brasileiros ainda devem arcar com o custo do teste DHE. Não foi possível obter o custo da realização do teste no Brasil. Na Europa, segundo Evans (2007), o valor é de 1.200 euros por ciclo da cultivar. 
As duas organizações mencionaram que as empresas holandesas, detentoras de grande know-how em floricultura, aproveitam-se dos laços culturais com a cidade de Holambra para expansão no mercado, inibindo, de alguma forma, o desenvolvimento de empresas nacionais. Segundo os entrevistados, os grupos de origem estrangeira, por sua capacidade de organização e gestão, fizeram com que as regras da legislação passassem a valer na prática. Esses grupos profissionalizados já estavam preparados para o modelo introduzido pela LPC e, segundo a ProClone, concentram os benefícios gerados pela lei.

Para Louwaars et al. (2003), um amplo esforço é necessário para familiarizar os agentes com as regras de um sistema de PVP. Na maioria dos países industrializados, os envolvidos tiveram a oportunidade de ajustamento ao longo de várias décadas. Já nos países em desenvolvimento, um sistema bastante sofisticado foi desenvolvido em curto espaço de tempo. Como consequência, empresas privadas multinacionais com longa experiência em sistemas de PVP podem ter vantagens em relação aos agentes locais.

Os custos do processo de proteção foi uma justificativa de ambas as organizaçóes para o número reduzido de variedades brasileiras protegidas. Ponderou-se que tais custos podem ser um fator limitante para a proteção de flores e plantas ornamentais, pois, muitas vezes, o mercado para certas variedades é tão restrito que o investimento na proteção não é compensado pelo retorno financeiro proporcionado pela cobrança de royalties.

Além das taxas administrativas pagas ao SNPC, que são comuns tanto aos brasileiros quanto aos estrangeiros, os melhoristas brasileiros precisam arcar com os custos dos testes de distinção, homogeneidade e estabilidade (DHE). Considerando que o nível de organização e estruturação das instituições brasileiras de melhoramento está muito aquém das estrangeiras, percebe-se que o custo para a obtenção da proteção tem um peso importante para o desenvolvimento dessa atividade no Brasil.

Para os entrevistados, o dispositivo de uso próprio desestimula os investimentos em melhoramento de flores, porém, o baixo desenvolvimento desta atividade no âmbito nacional não é atribuído apenas à presença do dispositivo na legislação. Entre os motivos relacionados pelos entrevistados, destacam-se o relativo desconhecimento da lei por instituições nacionais que ainda não aprenderam como usufruir das possibilidades propiciadas pelo instrumento e os altos custos incorridos para o desenvolvimento de novas variedades. No caso do IAC, a falta de uma política estruturada para lidar com a proteção de cultivares é motivo adicional para a organização ainda não ter variedades ornamentais protegidas. 


\subsection{Melhoristas estrangeiros}

O universo dos melhoristas estrangeiros com variedades de rosas, gérberas e alstroemerias protegidas e/ou comercializadas no Brasil, no período em que a pesquisa foi realizada, era composto por 18 empresas. ${ }^{10}$ Foram contempladas sete delas, em cinco entrevistas realizadas com os seus representantes no país.

Os melhoristas de rosas entrevistados respondiam por 54\% das variedades desse gênero protegidas no Brasil. Os melhoristas de gérberas entrevistados eram proprietários de $72 \%$ das variedades protegidas. No caso da alstroemeria, as entrevistas cobriram $100 \%$ das variedades protegidas. Os entrevistados foram: Tantau, Nirp, Lex, Preesman, Könst, Florist de Kwakel e Van Zanten Plants. Os dois primeiros são, respectivamente, de nacionalidades alemã e franco-italiana e os outros são holandeses. O Quadro 2 sumariza as implicaçōes extraídas dessas entrevistas.

Apesar de algumas opiniōes isoladas, verifica-se convergência entres os melhoristas estrangeiros sobre a maior parte dos temas abordados. A respeito da influência da sanção da LPC na decisão das empresas de investir no Brasil, todos foram categóricos em afirmar que não teriam estabelecido negócios no país se a lei não tivesse sido promulgada.

Com exceção de um respondente, todas as outras empresas entrevistadas afirmaram que a maneira como o uso próprio está estabelecido torna a lei ineficaz para plantas de reprodução vegetativa e assim influencia negativamente seus negócios no Brasil. Três deles confirmaram que o modelo de negócio estabelecido no Brasil seria diferente, caso o dispositivo fosse excluído para as flores e plantas ornamentais.

A Nirp afirmou que considera estabelecer unidades de pesquisa em melhoramento no país e a Preesman acredita que, além de investir em pesquisa para o Brasil e em unidade de pesquisa no Brasil, poderia aumentar o leque de produtores atendidos. Segundo a empresa, o ambiente ficaria mais seguro para trabalhar com pequenos produtores que hoje não têm acesso às novas variedades por conta do risco que o dispositivo de uso próprio confere. ${ }^{11}$

Para garantir a apropriação sobre os DPIs, todos os melhoristas de flores com atuação no Brasil baseiam seus negócios com os produtores em contratos em que uma cláusula de não propagação por alegação de uso próprio é obrigatória. Conforme lembrado por um dos entrevistados, embora o contrato seja uma maneira de minimizar o impacto da brecha na lei, também acarreta custos adicionais.

10 Incluídas aquelas que tiveram variedades trazidas ilegalmente ao Brasil e que não possuem representação no país.

11 São agricultores de Nova Friburgo (Rio de Janeiro), Gramado (Rio Grande do Sul) e Barbacena (Minas Gerais). 


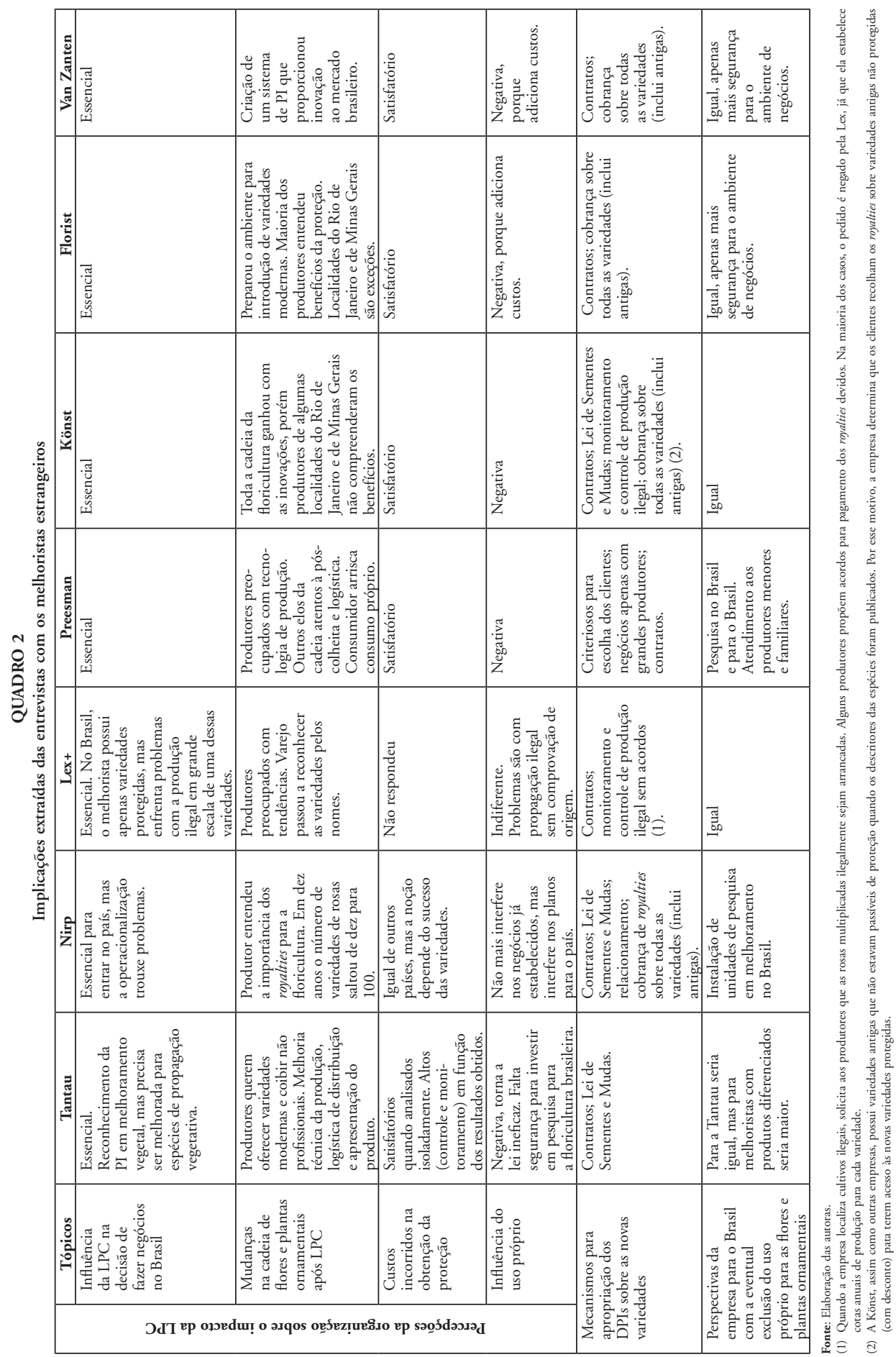


Eaton (2007) afirma que o uso de contratos implica custos de transação que impedem que o fluxo de benefícios da inovação seja completamente capturado pelos melhoristas. Além dos custos para o desenho dos contratos, os melhoristas incorrem em custos de transação gerados pelo controle e monitoramento que alguns deles realizam para coibir a pirataria e buscar maior apropriação de seus direitos.

Nota-se que os melhoristas utilizam os contratos também como uma maneira de obter remuneração sobre as variedades que não estão protegidas. Ao atrelarem a disponibilização das novas variedades protegidas ao pagamento de royalties sobre variedades antigas, eles conseguem arrecadação sobre variedades que não puderam ser protegidas em função dos prazos estipulados na lei brasileira.

Os entrevistados mencionaram que é possível recorrer à Lei de Sementes e Mudas como uma maneira de evitar a alegação de uso próprio por aqueles produtores que não têm como comprovar a origem do material propagativo utilizado. Como usuário de material propagativo, o produtor precisa esclarecer a origem do material utilizado para o plantio. Caso não seja capaz de demonstrar que adquiriu ou produziu a muda dentro dos critérios estabelecidos pela Lei de Sementes e Mudas, ele pode ser multado por acesso indevido ao material propagativo de variedades protegidas sem comprovação de origem. ${ }^{12}$

No entanto, verificou-se que não está claro para todos os melhoristas que essa possibilidade é concreta, em função da complexidade que a lei apresenta, bem como de regulamentação complementar necessária que ainda não havia sido publicada à época das entrevistas.

Os custos incorridos na obtenção do certificado de proteção não são uma queixa entre os melhoristas estrangeiros. Porém, dois entrevistados fizeram a seguinte ressalva: quando se analisam apenas os valores monetários das taxas administrativas pagas ao SNPC e a aquisição de testes DHE que já vêm prontos da Europa, os custos são plausíveis. Todavia, como o Brasil não possui um mecanismo ágil e capaz de monitorar com eficácia a pirataria, os custos tornam-se elevados, já que os obtentores precisam arcar com gastos que envolvem monitoramento e controle das variedades protegidas.

12 A Lei de Sementes e Mudas foi construída juntamente com a LPC, apesar de ter sido sancionada seis anos depois, em 2003. Ela estabelece que, com exceção dos agricultores familiares, assentados da reforma agrária e indígenas, os produtores agrícolas devem comprovar que o material propagativo utilizado para produção de mudas é originário de estabelecimentos inscritos no Mapa. Estes estabelecimentos, por sua vez, devem ter autorização do respectivo detentor do direito de propriedade da cultivar, no caso de cultivar protegida, para utilização do material. 


\subsection{Entrevistas com produtores de flores}

Foram entrevistados 16 produtores; a amostra alcançou 2\% e 5\% da área plantada com flores, respectivamente, em Atibaia e Holambra, dois importantes municípios no cultivo de flores. Produtores de outros importantes municípios também foram entrevistados. O Quadro 3 sumariza as implicações extraídas das entrevistas. ${ }^{13}$

\section{QUADRO 3}

Implicações extraídas das entrevistas com os produtores de flores

\begin{tabular}{|c|c|}
\hline Questão & Produtores \\
\hline $\begin{array}{l}\text { Como a cadeia } \\
\text { brasileira de flores e } \\
\text { plantas ornamentais foi } \\
\text { impactada pela LPC? }\end{array}$ & $\begin{array}{l}\text { - A maioria (75\%) considera o impacto positivo. } \\
\text { - Principais motivos: variedade (mais opções) de novas cultivares; } \\
\text { qualidade; menor custo em função da utilização de cultivares mais } \\
\text { resistentes. } \\
\text { - Metade considera o royalty mais um investimento do que um custo } \\
\text { de produção. } \\
\text { - A maioria considera que as variedades protegidas são mais } \\
\text { produtivas. } \\
\text { - Principais motivos para o pagamento de royalties: remunerar o } \\
\text { trabalho dos melhoristas e financiar novas pesquisa; e no futuro não } \\
\text { terão acesso aos novos materiais caso não paguem os royalties. } \\
\text { - Pagamento de royalties subentende maior nível tecnológico } \\
\text { (produção em estufa). }\end{array}$ \\
\hline
\end{tabular}

Fonte: Elaboração das autoras.

Em referência ao impacto da LPC no mercado de flores, $75 \%$ dos produtores (nove da região de Holambra e três de Atibaia) afirmaram que a lei foi muito positiva ou positiva. Os principais argumentos para as respostas positivas foram: "produtos mais evoluídos que atendem novas exigências"; "novas oportunidades para produtores e consumidores"; "qualidade do produto"; "assistência técnica"; "possibilitou melhor penetração no mercado, diminuição de perdas e diferenciação"; "diminuição de custos em função de melhor qualidade obtida"; "variedades são mais resistentes às doenças o que reduz o custo total"; "incentiva a pesquisa de novidades, a pesquisa é necessária, o produtor precisa de variedades mais resistentes".

Alguns produtores apontaram que a LPC "moralizou o mercado", mas que ainda há trabalho a ser feito no sentido de melhorar a fiscalização e aprimorar a legislação para facilitar o cumprimento pelo produtor. Aqueles que não avaliaram o impacto da LPC como positivo argumentaram não ter notado mudanças no mercado.

13 Foram entrevistados pequenos, médios e grandes produtores. A área de produção dos entrevistados variou de 0,8 a 20 hectares, com média de seis hectares. Os produtores foram diferenciados em relação à região de produção, sendo nove na região de Holambra e sete agrupados como produtores de Atibaia. 
Metade dos produtores entrevistados considera o pagamento de royalties mais um investimento do que propriamente um custo de produção. Mesmo no caso dos que consideram um custo, a maioria pondera que é um gasto com o qual os produtores devem arcar para ter acesso às novas variedades.

Em relação ao custo que o royalty representa no custo total de produção, $37,5 \%$ dos respondentes não souberam precisar o valor ou preferiram não se manifestar, pois consideram que este valor é relativo, em função do sucesso que cada variedade alcança no mercado. $\mathrm{O}$ custo do royalty pode ser diluído em função da aceitação da flor no mercado.

Entre aqueles que responderam, os valores citados foram bem discrepantes, numa faixa que vai de $0,5 \%$ a $5 \%$ do custo total, indicando que o custo pode realmente variar em função do sucesso da variedade e/ou que os produtores não têm pleno conhecimento de sua estrutura de custos.

Foram encontrados indícios de que o pagamento de royalties é mais comum quando a produção é realizada em ambiente protegido (estufa). Considerando que a qualidade das flores produzidas em ambiente protegido é muito superior à daquelas produzidas em campo aberto, alguns produtores afirmaram que o investimento em variedades protegidas não é viável para flores produzidas em campo, em virtude do baixo preço que estas alcançam no mercado.

Aqueles que produzem na região de Holambra têm a percepção de que mais produtores pagam royalties do que é percebido pelos entrevistados da área de Atibaia. Entre os primeiros, 55,5\% acreditam que a maioria dos produtores paga royalties e $45,5 \%$ acham que apenas alguns pagam royalty. No caso da região de Atibaia, apenas um produtor acredita que a maioria pague royalties, enquanto $71 \%$ acreditam que apenas alguns pagam royalties e um produtor não conhece quem pague.

Tal observação é complementada por outra: na região de Holambra, 55,5\% acreditam que alguns produtores recolhem royalties também sobre variedades que não estão protegidas, enquanto em Atibaia todos foram unânimes em afirmar que não conhecem quem pague royalty sobre variedades não protegidas.

Quando indagados sobre mudanças no lucro alcançado depois que passaram a pagar royalties, $50 \%$ garantiram que os lucros cresceram porque o preço alcançado pelo produto aumentou mais do que o custo de produção.

Os produtores de Holambra afirmaram que, na região, quem não paga precisa vender em um "mercado mais escondido". Segundo um dos respondentes, existe consenso entre os produtores que procuram conduzir suas atividades no âmbito da 
legislação, de que o pagamento de royalties melhora a qualidade das variedades e é um compromisso com o mercado.

Os principais motivos citados pelos entrevistados como justificativa para o pagamento de royalties indica que os produtores o fazem em função de uma maior conscientização sobre a importância da PI para a inovação e da preocupação em honrar os contratos para continuar com acesso às novidades, do que propriamente pela preocupação em cumprir a legislação.

A comparação entre as regiōes de Holambra e Atibaia mostrou que os produtores da segunda região têm uma percepção menos positiva sobre a LPC, além de serem os únicos que enxergam o royalty meramente como mais um custo de produção. Tais constatações reforçam o que foi identificado nas entrevistas com os melhoristas: os benefícios da LPC ainda estão mais regionalizados para os produtores de Holambra, ou de origem holandesa, até porque são os mais comprometidos com a proteção de cultivares.

\subsection{Entrevistas com distribuidores de flores ${ }^{14}$}

Foram entrevistados distribuidores com atuação em Campinas, São Paulo (capital), Maceió, Recife, Salvador, Natal, Distrito Federal e Santa Catarina. Ao todo cinco empresas foram entrevistadas. As principais implicações obtidas estão compiladas no Quadro 4.

\section{QUADRO 4}

Implicações extraídas das entrevistas com os distribuidores de flores

\begin{tabular}{|l|ll|}
\hline \multicolumn{1}{|c|}{ Questão } & \multicolumn{1}{c|}{ Distribuidores } \\
\hline & - $\begin{array}{l}\text { Estão bem informados sobre a LPC e a maioria concorda } \\
\text { que a lei foi positiva para o mercado. }\end{array}$ \\
Como a cadeia brasileira de & $\begin{array}{l}\text { Aqueles que reconhecem o impacto positivo } \\
\text { responsabilizam a lei pelas principais mudanças positivas } \\
\text { flores e plantas ornamentais } \\
\text { foi impactada pela LPC? }\end{array}$ & $\begin{array}{l}\text { ocorridas na floricultura nacional. } \\
\text { Motivos: aprimoramento da qualidade das flores } \\
\text { comercializadas; profissionalização do setor; grande } \\
\text { número de variedades à disposição. } \\
\text { Reconhecem atributos diferenciados nas variedades } \\
\text { protegidas embora seus clientes (varejistas) reconheçam } \\
\text { apenas parcialmente. }\end{array}$ \\
\hline
\end{tabular}

Fonte: Elaboração das autoras.

14 Empresas que compram flores em grande quantidade nos centros de comercialização da regiāo de Holambra e nas centrais de abastecimento, como Ceagesp e Ceasa, possuem estrutura própria de distribuição e vendem para os varejistas. 
Apesar de não terem envolvimento direto com a proteção de cultivares, verificou-se que os distribuidores estão bem informados sobre o tema. ${ }^{15}$ Quatro respondentes destacaram que o impacto da LPC no mercado brasileiro de flores foi muito positivo ou positivo e um entendeu que o impacto foi neutro.

Três entrevistados afirmaram que a lei foi positiva, pois possibilitou o aprimoramento da qualidade das flores comercializadas no país. Dois entrevistados concordaram que a LPC contribuiu para a profissionalização do setor. Um deles lembrou que a lei favoreceu a gama abrangente de variedades que podem ser oferecidas aos clientes, ao contrário do que ocorria no passado. $\mathrm{O}$ mesmo respondente frisou também que os lançamentos de variedades já são quase simultâneos entre a Europa e o Brasil. O entrevistado que foi neutro sobre o impacto da LPC justificou que ainda existem varejistas que preferem continuar trabalhando com as variedades antigas tradicionais.

Os entrevistados listaram aqueles que, em sua opinião, são os principais atributos que diferenciam as flores protegidas daquelas que não são protegidas: qualidade (citada três vezes); tamanho do botão (duas vezes); maior durabilidade (uma vez); cores (uma vez); folhagem perfeita (uma vez); tamanho (uma vez); número de pétalas (uma vez); e beleza (uma vez).

A respeito da diferenciação, por seus clientes, entre as variedades protegidas e as não protegidas, um dos entrevistados afirmou que o varejo ou consumidor final não reconhece a existência de atributos diferenciados entre elas e que o preço conseguido por ambas é o mesmo. Dois entrevistados mencionaram que alguns percebem os atributos diferenciados nas variedades protegidas, enquanto outros não. Outros dois distribuidores comentaram que, na maioria das vezes, conseguem melhores preços nas variedades protegidas, pois o mercado já percebeu que essas flores possuem atributos diferenciados.

De maneira geral, os entrevistados notaram que o mercado evoluiu e se modernizou em consequência da LPC. Eles destacaram, principalmente, a grande variedade de flores que podem ser ofertadas aos consumidores. Constatou-se a conscientização dos distribuidores sobre a necessidade de recompensar os melhoristas pelos benefícios proporcionados à floricultura, para que retornem à cadeia na forma de mais inovaçôes. Entretanto, dois entrevistados ponderaram que a lei foi positiva apenas para os produtores que investem na sua produção e se diferenciam, enquanto os que não pagam royalties correm o risco de ter sua produção interditada.

15 Os entrevistados indicaram variedades protegidas com um índice de $88 \%$ de acerto. 


\subsection{A proteção de cultivares no Brasil: alguns números}

Segundo dados do Registro Nacional de Cultivares (RNC), existem mais de 25 mil cultivares registradas para comercialização, das quais cerca de 1.600 são variedades protegidas. Destas últimas, $18 \%$ referiam-se a plantas ornamentais, sendo 92 variedades de rosas, 21 de gérberas e 18 de alstroemerias (MAPA, 2012). ${ }^{16}$

Melhoristas holandeses, alemães e franceses dominam o mercado, detendo, juntos, mais de $90 \%$ das rosas protegidas. No caso de gérberas e alstroemerias, todos os melhoristas com variedades presentes no Brasil são holandeses.

Foi analisado o tempo transcorrido entre a emissão dos certificados de proteção de variedades de rosas na Europa e no Brasil. O Gráfico 1 mostra a evolução ao longo dos anos.

\section{GRÁFICO 1}

Tempo médio transcorrido entre a concessão de proteção de variedades de rosas na UE e no Brasil

2001-2009

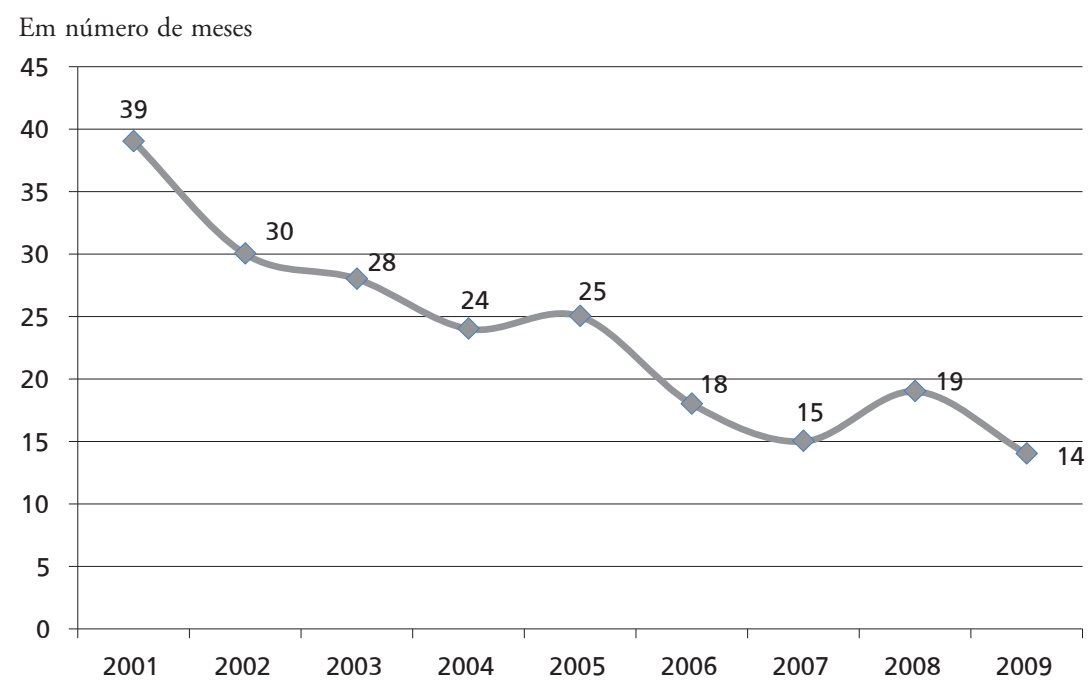

Fonte: Mapa (2012) e CPVO (2011). Elaboração das autoras.

O Gráfico 1 apresenta, para todas as variedades de rosas protegidas no Brasil, o tempo médio transcorrido entre a concessão da proteção na UE e no Brasil. O eixo $\mathrm{X}$ mostra o ano em que foi emitido o certificado de proteção na UE e o eixo $\mathrm{Y}$ o tempo, em meses, transcorrido para a emissão do certificado no Brasil. Por exem- 
plo: as variedades que tiveram o certificado de proteção emitido na UE em 2009 tiveram, em média, o certificado de proteção emitido no Brasil 14 meses depois.

Observa-se uma tendência de diminuição no tempo transcorrido entre a concessão de proteção na Europa e no Brasil, um indicativo de que, com o amadurecimento da LPC, as variedades protegidas introduzidas no Brasil estão cada vez mais em sintonia com as variedades lançadas nos principais mercados de flores. Trata-se de evidência de que o mercado brasileiro de rosas vem se modernizando e acompanhando mais prontamente as tendências mundiais.

\subsection{Síntese das implicações dos resultados para o problema estudado}

Este artigo procurou explorar como a cadeia brasileira de flores e plantas ornamentais é impactada pela LPC. A introdução de um sistema de PVP no Brasil, por meio da LPC, trouxe diversos benefícios. O ambiente institucional estabelecido a partir da lei está criando um círculo virtuoso para a floricultura brasileira.

A LPC significou o reconhecimento da PI em melhoramento vegetal e, por isso, foi determinante para a entrada de empresas de melhoramento no país. A introdução, por essas empresas, de novas cultivares com atributos diferenciados está modernizando a floricultura brasileira.

Os produtores mais dinâmicos e profissionalizados compreenderam que o investimento em novas variedades configura-se em melhores oportunidades de negócios diante do mercado consumidor e que, para que essas oportunidades sejam perpetuadas, é preciso remunerar aquele que desenvolve as novas variedades. Assim, ao respeitarem os DPIs dos obtentores, os produtores contribuem para a continuidade da pesquisa e também asseguram o acesso permanente aos novos materiais.

A utilização de variedades modernas desperta no produtor a preocupação com o restante da sua estrutura produtiva. Para extrair o melhor resultado possível das variedades pelas quais os royalties são pagos, ele entendeu que é importante investir também em material propagativo de qualidade e cultivo em ambiente protegido entre outras tecnologias.

Evidenciou-se que o mercado brasileiro tem se modernizado em termos tanto de maior variedade de produtos ofertados, como de qualidade dos produtos. Os distribuidores entrevistados reconheceram que tais benefícios foram proporcionados pela LPC. Adicionalmente, a análise do número de certificados de proteção demonstrou, para o caso das rosas, que a floricultura nacional tem se atualizado progressivamente diante das principais tendências e lançamentos do mercado europeu. 


\subsubsection{Peculiaridades do impacto da LPC: desigualdade nos resultados alcançados}

A LPC cumpriu parcialmente um dos principais objetivos de um sistema de PVP que é a promoção da inovação (UPOV, 2005). Muito embora o aprimoramento da floricultura brasileira tenha sido reconhecido por produtores e distribuidores, o presente trabalho identificou também que esse impacto ainda não ocorreu de forma homogênea. Os resultados mais positivos estão restritos a algumas regiōes produtoras, especialmente aquelas em que atuam produtores de origem holandesa. Outras regiōes brasileiras foram indicadas como locais onde os direitos de obtentores não são respeitados.

$\mathrm{Na}$ região de Holambra, há indícios de que se criou uma consciência coletiva sobre a importância dos DPIs. É possível supor que os laços sociais entre os descendentes de holandeses desempenham um forte papel coercitivo no respeito à PI. Ou seja, apesar de haver uma brecha na lei, os produtores de origem holandesa seriam mais rigorosos no cumprimento dos contratos por medo da exclusão social.

Por outro lado, para as organizaçôes brasileiras entrevistadas, o impacto da LPC ainda é relativamente pequeno. Embora a lei tenha conferido um ambiente mais favorável para a apropriação dos DPIs na condução das pesquisas em melhoramento, ela, por si só, não tem sido suficiente para impulsionar a pesquisa brasileira em flores e plantas ornamentais. Restrições de cunho financeiro ainda são barreiras ao maior investimento nesta atividade.

Ademais, verificou-se que os agentes mais bem organizados usam melhor os DPIs a seu favor, como é o caso dos melhoristas estrangeiros que consistem, em sua maioria, de empresas bem estruturadas que aproveitam melhor os benefícios proporcionados pelo regramento, em comparação com as organizações de melhoramento brasileiras.

No Brasil, a legislação é recente e ainda requer um período de amadurecimento até que os agentes identifiquem como podem utilizá-la para favorecer o desenvolvimento econômico. A proteção de cultivares é um instrumento que privilegia o detentor do direito e possibilita que o próprio delibere sobre a melhor maneira de disponibilizar esse direito para atender apropriadamente as diversas classes de agricultores, desde o pequeno produtor familiar até o empresário rural. 


\subsubsection{A influência do uso próprio na cadeia brasileira de flores e plantas ornamentais}

Inicialmente aventou-se que o dispositivo de uso próprio, conforme estabelecido, poderia levar a cadeia produtiva em questão a um desempenho inferior. Constatou-se que, de fato, tal dispositivo impede uma concretização mais ampla dos benefícios que se espera alcançar após a implantação de um sistema de PVP. Para que obtenham a apropriação esperada sobre seus direitos, os melhoristas precisam recorrer a mecanismos que minimizem o efeito negativo do uso próprio. Todavia, tais mecanismos incorrem em custos de transação.

Por meio de contratos com cláusulas que restringem o uso próprio, é possível evitar o risco de não apropriação dos direitos, mas os melhoristas precisam arcar com os custos de enforcement desses contratos. Há também esforços de monitoramento e controle de cultivos piratas e para a construção de confiança e reputação com os produtores clientes.

Conforme sinalizado por Eggertsson (1990), o custo do enforcement para apropriação dos DPIs está sendo influenciado pelo ambiente institucional, enfraquecido em função da incidência do dispositivo de uso próprio na cadeia de flores e plantas ornamentais.

Posto de outra forma, como os DPIs não estão bem definidos, há custos de transação para usar o mercado que implicam a formatação de contratos. No caso dos produtores de origem holandesa, a coerção social (enforcement social) é um facilitador do cumprimento dos contratos. Nestes casos, os acordos entre as partes, mais do que a legislação, têm papel importante no disciplinamento do mercado para o respeito à PI. Conforme se verificou, quem viola os contratos está "fora do jogo" no acesso continuo às variedades modernas.

Alguns melhoristas que atuam no Brasil não têm segurança em trabalhar com produtores que não sejam profissionalizados, em virtude do risco representado pela alegação de uso próprio e violação de contratos. Como decorrência, verifica-se a exclusão de pequenos produtores familiares ao acesso à inovação representada pelas variedades modernas de flores.

A Lei de Sementes e Mudas é complementar à LPC como uma solução limitadora do uso próprio. Contudo, este propósito não está claro para todos os agentes e, inclusive, foi percebido tardiamente em alguns casos. O fato evidencia a existência de uma lacuna no sistema de PVP brasileiro que, conforme adverte 
Coase (1960), dificulta a adequação da alocação e manutenção dos DPIs aos titulares das variedades.

Além dos custos de transação incorridos pela falta de uma limitação clara à prática de uso próprio e da falta de clareza com que as duas leis se integram, outros obstáculos provocados pelo uso próprio impedem um impacto mais positivo da LPC. Foi mencionado nas entrevistas que o dispositivo inibe investimentos em unidades de pesquisa em melhoramento das empresas estrangeiras no Brasil e intimida possíveis interessados em investir no setor, no âmbito doméstico.

\section{Considerações finais}

A sanção da LPC significou o reconhecimento da PI em melhoramento vegetal e, por isso, foi determinante para a entrada de empresas de melhoramento de flores no Brasil. Por sua vez, a introdução de novas cultivares por essas empresas trouxe inovação para a floricultura brasileira. Em 2010, mais de 100 variedades de rosas estavam disponíveis para o consumidor, ao passo que dez anos antes eram pouco mais de dez.

Embora o aprimoramento da floricultura tenha sido reconhecido pela maioria dos agentes, verificou-se que os principais resultados ficaram restritos especialmente às organizações estrangeiras. As organizações brasileiras ainda não conseguem competir em igualdade. Nota-se que segmentos estruturados e organizados conseguem usufruir melhor dos DPIs proporcionados pelo regramento institucional.

O dispositivo de uso próprio impede a concretização ampla dos benefícios esperados de um sistema de PVP. Uma vez que os DPIs não estão claramente definidos, criam-se custos de transação em função da necessidade da concepção de estruturas de monitoramento e de contratos que permitam adequada apropriação dos direitos pelos melhoristas. O dispositivo de uso próprio, como concebido, ainda limita o nível de investimento dos melhoristas no país.

O dispositivo que foi inserido na legislação para resguardar os pequenos produtores acabou por excluí-los. Enfatiza-se, portanto, que apenas com clareza na legislação esse grupo terá acesso às variedades protegidas.

A sanção da LPC forneceu um sinal de compromisso, por parte do Estado, em melhorar o ambiente institucional para a realização de negócios e contratos no país. Todavia, para que a lei evolua no sentido de propiciar mais benefícios, como o acesso de pequenos produtores aos materiais inovadores e a geração de empregos por 
meio de investimentos no desenvolvimento do setor doméstico de melhoramento de flores, deve-se aperfeiçoar a legislação e empreender esforços para o balanceamento de interesses dos vários grupos envolvidos.

Um regramento único pode viabilizar diferentes níveis de proteção prevendo um nível mínimo de proteção e adicionando regras para culturas ou grupos de produtores específicos ou, então, criando um sistema forte, porém, delimitando exceçôes.

O artigo esclarece que a LPC gerou um ciclo virtuoso, mas tal conclusão suscita a importância de dar continuidade à investigação sobre o tema. Será que tal ciclo não estaria reforçando as barreiras à entrada das empresas domésticas no mercado em questão? Ou ainda, o que falta institucionalmente para o Brasil gerar tecnologia em melhoramento de flores? Essas são questôes que devem instigar futuras pesquisas sobre o tema.

\section{Referências bibliográficas}

AOKI, M. Linking economic and social-exchange games: from de the community norm to CSR. WP Stanford University and VCASI, 2007. Disponível em: <http://www.vcasi.org/ working-papers/wpapp1.html>. Acesso em: 14 jan. 2010.

AVIANI, D. de M. Os Direitos dos Obtentores: situação atual e perspectivas futuras. In: Conferência Ciopora sobre Direitos de Obtentores de Plantas. Campinas, 2009.

BRASIL. Presidência da República Lei de Proteção de Cultivares. Lei n. 9.456, de 25 de abril de 1997.

Lei de Sementes e Mudas. Lei n. 10.711, de 05 de agosto de 2003.

CARVAlHO, S. M. P. de. Propriedade intelectual na agricultura. Campinas, 2003. 183 f. Tese (Doutorado em Política Científica e Tecnológica) - Programa de Pós-Graduação em Política Científica e Tecnológica, Instituto de Geociências, Universidade Estadual de Campinas, Campinas, 2003.

COASE, R. H. The problem of social cost. Journal of Law and Economics, v. 3, n. 1, p. $1-44,1960$.

CPVO - Community Plant Variety Office. Applications and titles in force, 2011. Disponível em: <http://www.cpvoextranet.cpvo.europa.eu/WD140AWP/WD140Awp.exe/CONNECT/ ClientExtranet>. Acesso em: 31 jul. 2011.

DIEZ, M. C. F. The impact of plant varieties rights on research: the case of Spain. Food Policy, n. 27, p. 171-183, 2002. 
EATON, D. J. F. Intellectual property rights in plant breeding and biotechnology: a comparative institutional analysis. In: Conference of the International Society for the New Institutional Economics, 11. Reykjavik, 2007. Conference Programme... ISNIE, 2007. Disponível em: <http://www.isnie.org/programme-2007.html>. Acesso em: 14 jan. 2010.

. Trade and intellectual property rights in the agricultural seed sector. In: Conference of the International Society for the New Institutional Economics, 12. Toronto, 2008. Conference Programme... ISNIE, 2008. Disponível em: <http://www.isnie.org/isnie2008-program.html>. Acesso em: 29 Out. 2009.

EATON, D. J. F.; MEIJERINK G. Markets, institutional change and the new agenda for agriculture. Markets, Chains and Sustainable Development Strategy and Policy Paper, n. 6, p. 1-25, May 2007. Disponível em: <http://www.boci.-wur.nl/UK/Publications/>. Acesso em: 14 jan. 2010.

EATON, D. J. F.; VAN TONGEREN, F. W. Mixed incentive effects of IPRs in agriculture. In: Annual Conference of the International Consortium on Agricultural Biotechnology Research, 8. Ravello, 2004. Conference papers... ICABR, 2004. Disponível em: <http://www. economia.uniroma2.it/conferenze/icabr-2004/papers/default.asp>. Acesso em: 12 fev. 2010.

EGGERTSSON, T. Economic behavior and institutions. Cambridge: Cambridge University Press, 1990.

A note on the economic of institutions. In: ALSTON, L. J. et al. (Orgs.). Empirical studies in institutional change. Cambridge: Cambridge University Press, 1996, p. 6-24.

ENDRES, A. B.; GOLDSMITH, P. D. Alternative business strategies in weak intellectual property environments: a law \& economics analysis of the agro-biotechnology firm's strategic dilemma. Journal of Intellectual Property Law, v. 14, n. 2, p. 237-268, 2007.

FALCON, W. P.; FOWLER, C. Carving up the commons: emergence of a new international regime for germplasm development and transfer. Food Policy, n. 27, p. 197-222, 2002.

FUCK, M. P. A co-evolução tecnológica e institucional na organização da pesquisa agrícola no Brasil e na Argentina. Campinas: Unicamp, 2009. 177 f. Tese (Doutorado em Política Científica e Tecnológica) - Programa de Pós-Graduação em Política Científica e Tecnológica, Instituto de Geociências, Universidade Estadual de Campinas, Campinas, 2009.

GALLINI, N.; SCOTCHMER, S. Intellectual property: when is it the best incentive system? In: JAFFE, A. B. et al. (Orgs.). Innovation policy and the economy. Cambridge: MIT Press, v. 2, 2003, p. 51-78.

LENCE, S. H. et al. Welfare impacts of intellectual property protection in the seed industry. American Journal of Agicultural Economics, v. 87, n. 4, p. 951-968, 2005. 
LESSER, W. H. Assessing the implications of intellectual property rights on plant and animal agriculture. American Journal of Agicultural Economics, n. 79, p. 1584-1591, 1997.

LOUWAARS, N. P. Seeds of confusion: the impact of policies on seed systems. PhD dissertation. Wageningen: - Wageningen University, 2007.

LOUWAARS, N. P. et al. Impacts of strengthened intellectual property rights regimes on the plant breeding industry in developing countries: a synthesis of five case studies. Wageningen: Wageningen University, Centre for Genetic Resources, 2005 (report commissioned by the World Bank).

Framework for the introduction of Plant Variety Protection in developing countries. North-South policy brief. Wageningen: Wageningen University, n. 2, 2003.

MAPA - Ministério da Agricultura, Pecuária e Abastecimento. Registro Nacional de Cultivares (RNC). Registro Nacional de Cultivares: inclusōes, 2007. Disponível em: <http://www.agricultura. gov.br/images/MAPA/cultivares/snpc_06_-24_09_2007.htm>. Acesso em: 07 jul. 2009.

. Serviço Nacional de Proteção de Cultivares (SNPC). Pesquisa de cultivares protegidas, 2012. Disponível em: <http://extranet.agricultura.gov.br/php/snpc/cultivarweb/-cultivares_protegidas.php>. Acesso em: 30 jun. 2012.

NOGUEIRA, A. C. L. Propriedade intelectual em cultivares no Brasil: análise do marco regulador e comparação internacional. Informaçôes Fipe, n. 313, out. 2006.

NORTH, D. C. Institutions, institutional change and economic performance. Cambridge: Press Syndicate of the University of Cambridge, 1990.

SCOTCHMER, S. The political economy of intellectual property treaties. The Journal of Law, Economics, \& Organizations, v. 20, n. 2, p. 415-437, 2004.

SILVEIRA, J. M. F. J.; BORGES I. C. Um panorama da biotecnologia moderna. In: SILVEIRA J. M. F. J. et al. (Orgs.). Biotecnologia e recursos genéticos: desafios e oportunidades para o Brasil. Campinas: Instituto de Economia/Finep, 2004.

TRIPP, R. et al. Plant variety protection in developing countries: a report from the field. Food Policy, n. 32, p. 354-371, 2007.

Intellectual property rights: designing regimes to support plant breeding in developing countries. Washington: World Bank - Agriculture and Rural Development Department, 2006. Report 35517-GLB.

TRIPS - Agreement on Trade Related Aspects of Intellectual Property Rights.Annex 1C-legal instruments: results of the Uruguay round. Marrakesh, v. 31, 1994, p. 319-351. Disponível em: <http://www.wto.org/english/docs_e/legal_e/27-trips.pdf>. Acesso em: 10 fev. 2009. 
UPOV - Union pour la Protéction des Obtenciones Vegetales. UPOV Report on the impact of Plant Variety Protection. Geneva, 2005 (UPOV document n. 353(E)). Disponível em: <http://www.upov.int/en/about/pdf/353_Executive_-Summary.pdf>. Acesso em: 19 fev. 2009. VAN ROOIJEN, S. R. P. S. Proteção de cultivares no Brasil e seu impacto para o setor de flores e plantas ornamentais. Atibaia: ABPCflor Associação Brasileira de Proteção de Cultivares de Flores e Plantas Ornamentais, 2006.

VIEIRA, A. C. P. et al. Patenteamento da biotecnologia no setor agrícola no Brasil: uma análise crítica. Revista Brasileira de Inovação v. 9, n. 2, p. 323-354, 2010.

WILKINSON, J.; CASTELLI, P. G. A transnacionalização da indústria de sementes no Brasil: biotecnologias, patentes e biodiversidade. Rio de Janeiro: ActionAid Brasil, 2000. Disponível em: <http://www.actionaid.org.br/Portals/0/Docs/sementes.pdf>. Acesso em: 20 fev. 2009. 